\title{
Non-medical risk factors associated with postponing elective surgery: a prospective observational study
}

\author{
Julia Becker ${ }^{1}$, Gerald Huschak ${ }^{2}$, Hannes-Caspar Petzold ${ }^{1,3}$, Volker Thieme ${ }^{1}$, Sebastian Stehr ${ }^{1}$ and Sven Bercker ${ }^{1,3^{*}}$
}

\begin{abstract}
Background: Operation room (OR) planning is a complex process, especially in large hospitals with high rates of unplanned emergency procedures. Postponing elective surgery in order to provide capacity for emergency operations is inevitable at times. Elderly patients, residents of nursing homes, women, patients with low socioeconomic status and ethnic minorities are at risk for undertreatment in other contexts, as suggested by reports in the medical literature. We hypothesized that specific patient groups could be at higher risk for having their elective surgery rescheduled for non-medical reasons.
\end{abstract}

Methods: In this single center, prospective observational trial, we analysed 2519 patients undergoing elective surgery from October 2018 to May 2019. A 14-item questionnaire was handed out to illicit patient details. Additional characteristics were collected using electronic patient records. Information on the timely performance of the scheduled surgery was obtained using the OR's patient data management system. $6.45 \%$ of all planned procedures analysed were postponed. Association of specific variables with postponement rates were analysed using the MannWhitney $U$ test and Fisher's exact test $/ X^{2}$-test.

Results: Significantly higher rates of postponing elective surgery were found in elderly patients. No significant differences in postponing rates were found for the variables gender, nationality (Germany, EU, non-EU), native language, professional medical background and level of education. Significantly lower rescheduling rates were found in patients with ties to hospital staff and in patients with a private health insurer.

Conclusions: Elderly patients, retirees and nursing home residents seem to be at higher risk for having their elective surgery rescheduled. However, owing to the study design, causality could not be proven. Our findings raise concern about possible undertreatment of these patient groups and provide data on short-term postponement of elective surgery.

Trial registration DRKS00015836. Retrospectively registered.

Keywords: Operation room management, Cancellation of surgery, Undertreatment

*Correspondence: Sven.Bercker@medizin.uni-leipzig.de

${ }^{1}$ Department of Anesthesiology and Intensive Care Medicine, University

Hospital of Leipzig, Liebigstrasse 20,04103 Leipzig, Germany

Full list of author information is available at the end of the article

\section{Background}

Operating room (OR) scheduling is a complex process that is influenced by multiple variables. Stringent planning can lead to optimized utilisation of costly resources. Reliability of scheduling is critical and can be increased by good preoperative evaluation and patient preparation. Multiple surgical theatres that are used on an

(c) The Author(s) 2021. Open Access This article is licensed under a Creative Commons Attribution 4.0 International License, which permits use, sharing, adaptation, distribution and reproduction in any medium or format, as long as you give appropriate credit to the original author(s) and the source, provide a link to the Creative Commons licence, and indicate if changes were made. The images or other third party material in this article are included in the article's Creative Commons licence, unless indicated otherwise in a credit line to the material. If material is not included in the article's Creative Commons licence and your intended use is not permitted by statutory regulation or exceeds the permitted use, you will need to obtain permission directly from the copyright holder. To view a copy of this licence, visit http://creativecommons.org/licenses/by/4.0/. The Creative Commons Public Domain Dedication waiver (http://creativeco mmons.org/publicdomain/zero/1.0/) applies to the data made available in this article, unless otherwise stated in a credit line to the data. 
interdisciplinary basis and with a high percentage of unplanned cases can complicate scheduling. Optimizing OR scheduling has been subject to numerous studies to improve on-site processes using methods of operations research [1]. This is not to be discussed further here, even if such considerations touch on aspects of a potential undersupply of patients.

In spite of all attempts to master stable OR scheduling many variables remain unpredictable and acute cancellation of a planned surgery slot commonly occurs. Reasons are medical as well as structural and are attributable partly to the patient, OR capacity, OR team performance or inadequate planning. Decision making in this context should be performed in an objective manner. It has, however, been shown, that cancellation due to non-medical reasons is common.

Life-threatening emergencies have the greatest potential for short-term harm, but relevant consequences of postponing an elective or semi-elective intervention have also been described. In cancer patients, an increase in mortality has been shown as a consequence of long-term delay of operations [2]. Recently, medical and psychological effects of postponing operations have been described extensively during the Covid-19 pandemic, e. g. an increase in anxiety in cancer patients [3] or an increase in impairment of physical function in patients awaiting to undergo hip arthroplasty [4]. A UK network analysed the psychological and economic burden induced by socalled "winter cancellations" in the NHS. Over one third of patients reported substantial sadness, disappointment, anger and stress and worsening of symptoms [5]. This mainly refers to long-term postponement. Substantial data on effects of short-term postponement have not been published yet. However, there are some obvious risks that may be associated with rescheduling operations (e.g. higher risk for high blood sugar levels in diabetic patients, reduced fluid intake leading to acute kidney injury)-prolonged phases of preoperative stress and anxiety with possible implications for long-term mental sequelae i.e. PTSD or depression.

We conducted this study to describe non-medical risk factors for cancellation of elective surgeries.

\section{Methods}

This is an observational single-centre study situated at the University hospital of Leipzig. Between October 2018 and May 2019, all consecutive adult patients scheduled for elective surgery in the departments of 7 surgical subspecialties were screened during the preoperative anesthesia evaluation and asked to participate. The local ethics committee (Ref. No. 284/18) of the Medical Faculty of the University of Leipzig approved the study.
After informed consent was obtained, all patients were asked to complete a questionnaire including 14 items concerning age, gender, job (in particular if the patient had a professional medical background), place of birth, nationality, native language, living conditions (e.g. own flat or nursing home), kind of health insurance, if under legal supervision by a legal guardian, highest level of education and if patients had personal relationships to hospital staff. All questionnaires were available in German, English, French, Spanish, Turkish, Arab, Russian and Polish language.

Additional data were harvested using patient files and electronic OR schedules (SAP, SE Walldorf, Germany). As a routine procedure, every operation's urgency is rated on a 5-point scale from "elective" (E) to "immediate operation without delay" (N0) as defined by the German societies of anaesthesiology, surgery and operating room management. For this study, only patients scheduled for elective surgery were analysed. This defines a planned elective surgical procedure without any urgency. To determine if an operation was postponed, daily schedules were automatically saved at midnight and then later compared with operations started during the next $24 \mathrm{~h}$. If an elective surgery had had been scheduled on the OR plan at midnight and had not been started until the next $24 \mathrm{~h}$, it was categorized as postponed. All postponed operations were checked for plausibility and evaluated if postponing was due to medical reasons (e.g. worsening clinical condition of the patient) or due to organizational issues (e.g. over-planning of the surgical capacities, postponement due to an emergency) or if patients cancelled the operations themselves.

For analysis, potentially confounding categories were grouped (e.g. age groups, origin from Germany, European Union (EU) or non-EU states, public or private health insurance). We hypothesized that non-EU patients scheduled for surgery were more likely to be postponed. Data analysis was performed using Mann-Whitney $U$ test, Chi-Square test and Fisher's exact test (statistical software package SPSS (v25, Siemens, Germany)). For age, residents of nursery homes and retired patients a logistic regression was performed to analyse independency of these variables.

\section{Results}

During the study period $n=4396$ elective patients were scheduled for operation. Of those, $n=2521$ patients gave informed consent to participate in this study. 313 patients were excluded from further analysis due to several reasons. In $n=81$ cases the scheduled surgery was not performed at all and in $n=188$ inclusion criteria were violated (e. g. because priority changed from "elective" to a higher urgency category). 
42 questionnaires could not be evaluated due to incorrect or missing information. As 365 patients had more than one operation during the study period, 2589 data records were analysed.

Of the 2589 scheduled patients that were analysed, 167 were postponed (6.45\%). 2 patients cancelled the operation themselves and were excluded from further analysis. The mean age of all study participants was 54.9 years (SD 16.5 years). There were $52.1 \%$ male and $47.9 \%$ female patients. Data are shown in Table 1.

Mean age was 54.9 years and patients with cancelled operations were significantly older ( 59.4 vs. 54.6 years). In patients aged $>79$ years, the percentage of postponing was twice as high as in younger patients $<65$ years of age $(10.8 \%$ vs. $5.1 \%)$. Differences in postponing between the three age groups $(<65 \mathrm{y}, 65-79 \mathrm{y},>79 \mathrm{y})$ were significant $(p=0.001)$. In the univariate analysis, retirees $(p=0.005)$ and patients who lived in nursing homes $(p<0.001)$ had a significantly higher risk that elective surgery was not performed as scheduled. However, in the logistic regression only age turned out to be an independent risk factor.

Gender, origin or native language, and level of education did not have a significant effect on the incidence of postponing.

If patients had a personal relationship to staff members, the postponing rate was significantly lower $(4.3 \%$ vs.
6.8\%). The fact that patients had a professional medical background seemed to have no association with postponing. However, from the 48 physicians who were patients and participated in this study, only one case was postponed. Detailed results are shown in Table 1.

\section{Discussion}

With the data presented here, we could show that postponing of elective surgery was significantly associated with non-medical factors. Elder, retired patients, residents of nursing homes and those colonized with multidrug resistant (MDR) pathogens had an increased risk of an elective surgical case being postponed. The probability was significantly lower if patients had a private health insurance or had a personal relationship to hospital staff. In contrast to other studies origin, gender or being part of an ethnic minority was not associated with this effect. To our best knowledge, this is the first study addressing the association with non-medical factors with postponing elective surgery in a prospective, observational study.

The frequency of unplanned postponing was $8.9 \%$ in patients $\geq 65$ years and only $5.1 \%$ in patients $<65$ years. It is hardly possible to specify if this effect is due to procedural problems, to medical reasons or if this is an indicator for any kind of preventable undertreatment. In the medical literature, there are many examples showing undertreatment for elderly patients under specific

Table 1 Mean differences between groups. In brackets the distribution of the respective parameter within both groups

\begin{tabular}{|c|c|c|c|c|}
\hline & Operation as scheduled $(n=2422)$ & Operation postponed $(n=165)$ & $p$-value & $\begin{array}{l}\text { Odds ratio (OR) and } 95 \% \\
\text { confidence interval }(\mathrm{Cl})\end{array}$ \\
\hline Age (years, mean, SD) & $54.6 \pm 16.5$ & $59.4 \pm 15.8$ & 0.001 & \\
\hline Gender & $\begin{array}{l}52.1 \%(n=1261) \text { male } \\
47.9 \%(n=1161) \text { female }\end{array}$ & $\begin{array}{l}52.1 \%(n=86) \text { male } \\
47.9 \%(n=79) \text { female }\end{array}$ & 1.000 n.s & $\begin{array}{l}\text { OR: } 1.002 \\
{[C l 0.731 ; 1.374]}\end{array}$ \\
\hline Retirees & $35.5 \%(n=808)$ retirees & $47 \%(n=71)$ retirees & 0.005 & $\begin{array}{l}\text { OR: } 1.611 \\
{[C I 1.157 ; 2.243]}\end{array}$ \\
\hline Country of birth in EU & $96.8 \%(n=2303)$ EU origin & $96.9 \%(n=157)$ EU origin & 1.000 n.s & $\begin{array}{l}\text { OR: } 1.036 \\
{[C l 0.413 ; 2.598]}\end{array}$ \\
\hline Nationality EU country & $97.9 \%(n=2347)$ EU nationality & $98.8 \%(n=159)$ EU nationality & 0.463 n.s & $\begin{array}{l}\text { OR: } 1.694 \\
{[C I 0.408 ; 7.024]}\end{array}$ \\
\hline Native language German & $95.8 \%(n=2277)$ native language German & $97 \%(n=159)$ native language German & 0.684 n.s & $\begin{array}{l}\text { OR: } 1.411 \\
{[C I 0.567 ; 3.512]}\end{array}$ \\
\hline Nursing home residents & $0.58 \%(n=14)$ nursing home residents & $3 \%(n=5)$ nursing home residents & $<0.001$ & $\begin{array}{l}\text { OR: } 5.348 \\
{[C l 1.903 ; 15.034]}\end{array}$ \\
\hline Patients with private insurance & $9.5 \%(n=230)$ with private insurance & $3.6 \%(n=6)$ with private insurance & 0.008 & $\begin{array}{l}\text { OR: } 0.360 \\
{[C l 0.157 ; 0.822]}\end{array}$ \\
\hline Under legal supervision & $0.45 \%(n=11)$ under legal supervision & $2.4 \%(n=4)$ under legal supervision & 0.001 & $\begin{array}{l}\text { OR: } 5446 \\
{[C l 1,715 ; 17,292]}\end{array}$ \\
\hline Private relationship to staff & $20.3 \%(n=490)$ with relationship to staff & $13.4 \%(n=22)$ with relationship to staff & 0.033 & $\begin{array}{l}\text { OR: } 0.608 \\
{[C l 0.384 ; 0.963]}\end{array}$ \\
\hline Professional medical background & $\begin{array}{l}9.8 \%(n=237) \text { with professional medical } \\
\text { background }\end{array}$ & $\begin{array}{l}6.1 \%(n=10) \text { with professional medical } \\
\text { background }\end{array}$ & 0.132 n.s & $\begin{array}{l}\text { OR: } 0.593 \\
{[C l 0.308 ; 1.140]}\end{array}$ \\
\hline Colonization with MDR pathogens & $3.4 \%(n=83)$ with MDR & $10.3 \%(n=17)$ with MDR & $<0.001$ & $\begin{array}{l}\text { OR: } 3.237 \\
{[C I 1.872 ; 5.597]}\end{array}$ \\
\hline$>1$ surgical intervention & $\begin{array}{l}28.3 \%(n=686) \text { with }>1 \text { surgical interven- } \\
\text { tion }\end{array}$ & $\begin{array}{l}37.6 \%(n=62) \text { with }>1 \text { surgical interven- } \\
\text { tion }\end{array}$ & 0.013 & $\begin{array}{l}\text { OR: } 1.523 \\
{[C \mid 1.098 ; 2.113]}\end{array}$ \\
\hline
\end{tabular}


circumstances. In a recent analysis, DuMontier et al. reviewed different studies describing undertreatment of elderly patients with different malignancies [6]. Undertreatment was defined as receiving a less intensive therapy than currently recommended.

Another example of undertreatment in elderly patients is the quality of pain treatment. Bernabei et al. demonstrated that elderly patients with cancer residing in nursing homes were more likely not to receive any pain medication or a reduced intensity of pain therapy, even though pain was very frequent in those patients. They postulated that underreporting and underestimation of pain in elderly patients may have contributed to this finding [7]. It could be possible that elderly patients suffering from dementia are more often incapable of expressing their needs and therefore more likely to be disadvantaged.

It is obvious that there must have been a substantial overlap between patients $>65$ years, retirement and residents of nursing homes. Of all 879 retired patients 734 were $>64$ years. On the other hand only 2 of 14 patients from nursing homes were younger than 65 years.

Numerous studies analysed reasons for cancellation of elective surgery. The main focus of these previous investigations lay on optimizing perioperative processes and patient preparation [8-12], and only three of these studies identified groups with an elevated risk of being cancelled. These retrospective studies demonstrated an association between cancellation and age, socioeconomic status and gender. Cho et al. analysed more than 60,000 surgical interventions in a Korean University hospital and found $8 \%$ cancellations with a significant correlation of cancellation with increasing age. An Iranian group analysed the effect of a health care transformation plan on surgical cancellations and showed an association between the type of insurance, marital status, sex and surgical cancellations [13]. However, there are many differences between the corresponding national health care systems and the reasons for these effects most likely differ substantially.

Nevertheless, aspects of health inequality and undertreatment in certain groups are well described in developed countries and age as a risk factor for inadequate treatment has been shown in several areas of medicine [14-16]. On the other hand, there is a multitude of medical reasons to provide less invasive treatment to elder patients with multi-system physiological changes and it is hard to distinguish between a rational decision and undertreatment. However, some examples of less intense or frequent therapy show aspects of undertreatment and it can be assumed to be the result of a kind of misconception of healthcare providers. In contrast, we hypothesize that the effects in our study are rather unwanted in nature and due to procedural problems or possibly due to psychological effects. We strongly believe that awareness concerning this phenomenon is of high importance to avoid undertreatment in patients at risk.

This study has some limitations. First of all, this is a single-centre study and we can only hypothesize that the effects are generalizable. However, the examples discussed above from the medical literature suggest that these effects are present or even widespread in health care systems of developed countries. As the reason for cancellation was analysed retrospectively and could not be proven in any case as non-medical in nature, we could not exclude that postponing was due to medical reasons at least in some cases. Second, this study was not designed to give a precise analysis of underlying reasons for surgical delay or analysed conceptions of the physicians responsible. Strictly speaking, the data provides an association-causality can be assumed but is not proven.

Furthermore, the low response rate might represent a bias. In general, groups with lower level of education or language barriers tend not to take part in surveys and we cannot exclude that those groups were underrepresented in our study.

This is a pre-pandemic study. It has been estimated that the current COVID-19 pandemic will lead to 28,404,603 cancellations of elective operations [17]. This shortage of medical resources has the potential to heighten the unequal treatment of patients. Future efforts should be directed towards better describing risk factors for inequality, identifying groups at risk, and developing programs to protect these groups from undertreatment.

\section{Conclusions}

We demonstrated that elderly patients and nursing home residents planned for elective surgery have a higher incidence of case cancellation. We postulate that this association is due to a mixture of medical and non-medical reasons. These findings should lead to awareness towards possible undertreatment of vulnerable groups.

\section{Abbreviations}

OR: Operation room/Odds ratio; UK: United Kingdom; NHS: National Health Service; PTSD: Posttraumatic stress syndrome; SD: Standard deviation; MDR: Multi drug resistance; ICF: Informed consent form.

\section{Acknowledgements}

We acknowledge support from Leipzig University for Open Access Publishing.

\section{Authors' contributions}

$\mathrm{JB}, \mathrm{SB}$ and $\mathrm{GH}$ prepared the study protocol, questionnaire and informed consent form (ICF). JB conducted data acquisition. JB, GH, HCP, VT, SS and SB were involved in data analysis and preparation of the manuscript. 


\section{Funding}

Open Access funding enabled and organized by Projekt DEAL. The study was funded by institutional resources. Open access was funded by the OA fund of the University of Leipzig.

\section{Availability of data and materials}

The datasets used and analysed during the current study are available from the corresponding author on reasonable request.

\section{Declarations}

\section{Ethics approval and consent to participate}

The study was approved by the ethics committee of the medical faculty of the University of Leipzig. Ref. no.: 284/18-ek. All patients gave informed consent prior to participation. The consent form was approved by the ethics committee. The study has been carried out in accordance with the declaration of Helsinki and the applicable national regulations and laws.

\section{Competing interests}

The authors declare that they have no competing interests.

\section{Author details}

${ }^{1}$ Department of Anesthesiology and Intensive Care Medicine, University Hospital of Leipzig, Liebigstrasse 20, 04103 Leipzig, Germany. ${ }^{2}$ Operating Room Management, University Hospital of Leipzig, Leipzig, Germany. ${ }^{3}$ Clinical Ethics Committee, University Hospital of Leipzig, Leipzig, Germany.

Received: 17 March 2021 Accepted: 6 July 2021

Published online: 13 July 2021

\section{References}

1. Bercker S, Waschipky R, Hokema F, Brecht W. Effects of overlapping induction on the utilization of complex operating structures: estimation using the practical application of a simulation model. Anaesthesist. 2013;62(6):440-6.

2. Hanna TP, King WD, Thibodeau S, Jalink M, Paulin GA, Harvey-Jones E, O'Sullivan DE, Booth CM, Sullivan R, Aggarwal A. Mortality due to cancer treatment delay: systematic review and meta-analysis. BMJ. 2020;371:m4087.

3. Gultekin M, Ak S, Ayhan A, Strojna A, Pletnev A, Fagotti A, Perrone AM, Erzeneoglu BE, Temiz BE, Lemley B, Soyak B. Perspectives, fears and expectations of patients with gynaecological cancers during the COVID-19 pandemic: a Pan-European study of the European Network of Gynaecological Cancer Advocacy Groups (ENGAGe). Cancer Med. 2021;10(1):208-19.

4. Fahy S, Moore J, Kelly M, Irwin S, Kenny P. Assessing the attitudes, awareness, and behavioral alterations of patients awaiting total hip arthroplasty during the COVID-19 crisis. Geriatr Orthop Surg Rehabil. 22. Oktober 2020 [zitiert 23. Februar 2021];11. Verfügbar unter: https://www.ncbi.nlm.nih. gov/pmc/articles/PMC7588755/.

5. Herrod PJ, Adiamah A, Boyd-Carson H, Daliya P, El-Sharkawy AM, Sarmah PB, Hossain T, Couch J, Sian TS, Wragg A, Andrew DR. Winter cancellations of elective surgical procedures in the UK: a questionnaire survey of patients on the economic and psychological impact. BMJ Open. 2019;9(9):e028753.

6. DuMontier C, Loh KP, Bain PA, Silliman RA, Hshieh T, Abel GA, Djulbegovic B, Driver JA, Dale W. Defining undertreatment and overtreatment in older adults with cancer: a scoping literature review. J Clin Oncol Off J Am Soc Clin Oncol. 2020;38(22):2558-69.

7. Bernabei R, Gambassi G, Lapane K, Landi F, Gatsonis C, Dunlop R, Lipsitz L, Steel K, Mor V, SAGE Study Group. Management of pain in elderly patients with cancer. Systematic assessment of geriatric drug use via epidemiology. JAMA. 1998;279(23):1877-82.

8. Argo JL, Vick CC, Graham LA, Itani KMF, Bishop MJ, Hawn MT. Elective surgical case cancellation in the Veterans Health Administration system: identifying areas for improvement. Am J Surg. 2009;198(5):600-6.

9. Fayed A, Elkouny A, Zoughaibi N, Wahabi H. Elective surgery cancelation on day of surgery: an endless dilemma. Saudi J Anaesth. 2016;10(1):68-73

10. Hand R, Levin P, Stanziola A. The causes of cancelled elective surgery. Qual Assur Util Rev Off J Am Coll Util Rev Phys. 1990;5(1):2-6.

11. Cho HS, Lee YS, Lee SG, Kim JM, Kim TH. Reasons for surgery cancellation in a general hospital: a 10-year study. Int J Environ Res Public Health. 2019;16(1):7.

12. Solak AK, Pandza H, Beciragic E, Husic A, Tursunovic I, Djozic H. Elective case cancellation on the day of surgery at a general hospital in Sarajevo: causes and possible solutions. Mater Socio-Medica. 2019;31(1):49-52.

13. Miri Bonjar MR, Khammarnia M, Bakhshi M, Ansari-Moghaddam A, Okati-Aliabad H, Mohammadi M (2019) Impact of the health transformation plan on the number of surgical operations and their cancelation. INQUIRY: J Health Care Org, Prov, Financ 56:004695801984638

14. Fakhri B, Fiala MA, Tuchman SA, Wildes TM. Undertreatment of older patients with newly diagnosed multiple myeloma in the era of novel therapies. Clin Lymphoma Myeloma Leuk. 2018;18(3):219-24.

15. Owusu C, Lash TL, Silliman RA. Effect of undertreatment on the disparity in age-related breast cancer-specific survival among older women. Breast Cancer Res Treat. 2007;102(2):227-36.

16. Bratt O, Folkvaljon Y, Eriksson MH, Akre O, Carlsson S, Drevin L, Lissbrant IF, Makarov D, Loeb S, Stattin P. Undertreatment of men in their seventies with high-risk nonmetastatic prostate cancer. Eur Urol. 2015;68(1):53-8.

17. COVIDSurg Collaborative. Elective surgery cancellations due to the COVID-19 pandemic: global predictive modelling to inform surgical recovery plans. Br J Surg. 2020;107(11):1440-9.

\section{Publisher's Note}

Springer Nature remains neutral with regard to jurisdictional claims in published maps and institutional affiliations.
Ready to submit your research? Choose BMC and benefit from:

- fast, convenient online submission

- thorough peer review by experienced researchers in your field

- rapid publication on acceptance

- support for research data, including large and complex data types

- gold Open Access which fosters wider collaboration and increased citations

- maximum visibility for your research: over 100M website views per year

At BMC, research is always in progress.

Learn more biomedcentral.com/submissions 